\title{
Rearing and Colonization of Lutzomyia evansi (Diptera: Psychodidae), a Vector of Visceral Leishmaniasis in Colombia
}

\author{
James Montoya-Lerma ${ }^{+}$, Horacio Cadena-Peña, Consuelo Jaramillo-Salazar
}

Corporación Centro Internacional de Investigaciones Médicas- CIDEIM, Apartado Aéreo 5390, Cali, Valle, Colombia

The sandfly Lutzomyia evansi from a focus of visceral leishmaniasis in northern Colombia was reared and maintained under laboratory conditions for five generations. The average time for total development was 41.8 days (range $=35.1$ - 49.6) at $25^{\circ} \mathrm{C}$ and $89-95 \%$ of relative humidity. The mean number of eggs laid was lower in laboratory bred females either in pots (13.2 eggs/female) or vials (29.9 eggs/female) than in wild caught females (33.4 eggs/female). Immature mortality, mainly due to fungal and mite contamination, was higher during the first two instars than in the remaining immature stages. Adults were robust and healthy although difficult to feed on hamster or chick skin membrane. In summary, Lu. evansi is a colonizable species but requires specific conditions.

Key words: sandflies - colonization - Lutzomyia evansi - bionomics - sugar - rainfall

Information on basic aspects of the life cycle such as oviposition, development of immature stages, adult longevity and so on, represent important parameters towards understanding the biology of insect vectors of tropical diseases. In many instances (e.g. Culicidae and Reduviidae) aspects of their natural history can be gathered from field observations, however, in other vectors (e.g. sandflies), much information is only partly or rarely available from natural conditions. In these cases, colonization in the laboratory represents the most feasible and accessible source of information on these insects.

Theoretically, all sandfly species are able to be colonized given appropriate temperature, humidity and media resembling the natural conditions. The high number of sandfly species successfully colonized during the last two decades is testimony

\footnotetext{
J Montoya-Lerma, was supported by a training grant from the WHO/UNDP/World Bank Special Program for Tropical Disease Research (TDR) and the Consejo Nacional de Ciencia y Tecnología de COLCIENCIAS (Fondo BID-COLCIENCIAS). C Jaramillo and H Cadena were supported by the US National Institute of Allergy and Infectious Diseases, National Institutes of Health (NIH) Tropical Medicine Research Center (TMRC) grant.

${ }^{+}$Corresponding author. Fax: +6672989. E-mail: cideim@cali.cetcol.net.co

Received 4 June 1997

Accepted 5 November 1997
}

to this assertion (Killick-Kendrick et al. 1991, Lawyer et al. 1991). However, some species though reared through at least one generation, have not yet been colonized. Presumably, unknown factors that are not mimicked in the laboratory, and reflect the micro-environment of the species in nature have limited the ability to propagate these species.

In the total absence of Lutzomyia longipalpis, the recognized principal vector of visceral leishmaniasis in the New World, the sandfly Lu. evansi has been found to constitute a vector of this disease in Colombia (Travi et al. 1990) and probably in Venezuela (Bendezu et al. 1995). Given its great epidemiological importance, the bionomics of the former species has been extensively studied (Morrison 1994). Conversely, since the recent discovery of the involvement of $\mathrm{Lu}$. evansi in the transmission of visceral leishmaniasis, the information about the bionomics of this sandfly is either old and fragmentary or published in local journals of limited circulation (Mirsa 1953, Oviedo et al. 1995). The present communication reports and discusses laboratory experiences, in addition to field observations on the life cycle of $L u$. evansi in San Andrés de Sotavento (SAS). Our final goal was to obtain information on the biology of this species that might serve as the basis for future investigations on its biotope, vector competence and transmission dynamics.

\section{MATERIALS AND METHODS}

Wild sandflies were collected by Shannon trap in Gardenias and El Contento, two small villages 
situated in the municipality of SAS, Caribbean Coast of Colombia, which have been previously described (Montoya-Lerma \& Lane 1996). Immediately after capture, flies were kept inside Barraud cages with a wet sponge to provide a high relative humidity. Cages were transported to the field laboratory in polystyrene containers and on the same night of capture, flies were offered a blood meal from an hamster anaesthetized with 1:10 KetamineXylacine. Twenty-four hours after feeding, engorged flies were separated and held in cages at $28^{\circ} \mathrm{C}$ and $90 \%$ relative humidity (RH) until egg maturation. Cotton pads soaked in an aqueous sucrose solution were provided as food source.

Batches of up to 100 gravid females were put

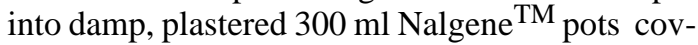
ered with a mesh cloth and kept inside polycarbonate boxes $(44 \times 22 \times 37 \mathrm{~cm})$. Pots were inspected and fly corpses removed daily up to five or six days post blood-feeding, when the majority of females had laid eggs and died. Some pots where kept in the San Andrés field laboratory but most of them were transported inside polystyrene boxes to CIDEIM headquarters (Cali, Colombia). In both cases, rearing of the immature stages followed a modified technique described by Modi and Tesh (1983). Briefly, immediately before larval hatching (which is indicated by the presence of caudal bristles and mouth parts visible through the egg shell), a small amount of larval food was sprinkled over the eggs. The food consisted of a matured 1:1 mixture of rabbit feces and rabbit chow enriched with 5\% liver powder. The food was dried and ground through different sieves (obtaining different size of grains to be used for each larval instar). The final product was aliquoted into small vials, sterilized, and kept frozen to reduce acari and fungal growth.

After hatching, larvae were inspected on a daily basis to control humidity and feed the larvae. Feeding and humidification were stopped when the majority of the larvae transformed to pupae.

After emerging, adults were counted, sexed and transferred to holding cages with access to saturated sugar solution and water. Four to five day old females were fed on anaesthetized hamsters. To identify the females and establish their fecundity and fertility rates, they were left in the cage for two days and then transferred to individual plastered vials $(4 \mathrm{~cm} \times 2.5 \mathrm{~cm})$, the bottom of which was lined with filter paper wetted with distilled water. The vials were capped with a cloth mesh, and placed in a polycarbonate boxes. To observe egg development, some females were dissected at $12 \mathrm{hr}$ intervals. The proportion of mature eggs (i.e. in IV or V stages of Christophers) from bred females was compared with that found in wild caught individuals. The remaining females were allowed to oviposit and when dead, identified and their eggs counted. Eggs from $\mathrm{Lu}$. evansi females were pooled into $300 \mathrm{ml}$ rearing pots, where the life cycle started again. The duration of various larval instars and their mortality rates were averaged from a variable number of individuals over several generations.

To assess if the kind of sugar intake has any effect on egg batch size, a batch of wild caught flies were kept under lab-field conditions but offering only water on cotton wool for $12 \mathrm{hr}$. After this period, flies were blood-fed on hamsters and individually transferred to plastered vials. Flies were evenly distributed between four groups. Each group of 15 individuals was offered one of the following saturated sugar solutions: glucose, sucrose, fructose or maltose, on small cotton wool pads placed on the top of each vial every day. All vials were placed inside clear plastic boxes at $95 \% \mathrm{RH}$, $29^{\circ} \mathrm{C}$ and kept in almost complete darkness for four days. During this interval, disturbance was kept to a minimum, only to change cotton pads and record survival rates. On the fourth day, flies were transferred to damp plaster-lined vials and kept as indicated above for an additional four days after which they were dissected. Fecundity was estimated as the sum of the fully matured eggs (V stage) that had been laid and those still retained in the abdomen after fly's death (Tesfa-Yohannes 1982).

\section{RESULTS}

A total of five cultures of $L u$. evansi was obtained under laboratory conditions at $25^{\circ} \mathrm{C}$ and 89 95\% RH in Cali. Two additional cultures were made in SAS $\left(28^{\circ} \mathrm{C}\right.$ and $\left.99 \% \mathrm{RH}\right)$. Data are based on five consecutive generations from each culture, excepting SAS, where only three generations were recorded.

The average time for the total development (i.e. between the blood meal intake and the first emergence of adults) of Lu. evansi was 41.8 days (range $=35.1-49.6$ ). From this period, the pre-oviposition (i.e. blood meal digestion and egg maturation) was 3.5 days (range 2-5); egg incubation required 6.5 days (6-7); larval molting (i.e. from larva I to larva IV) 9.8 days (8.6-15.9); pupa 10 days (9-11) and pupa to adult 9 days (8-10.1).

The mean number of eggs laid per female was affected by the type of container used for oviposition. Thus, a lower number of eggs was obtained using pots (13.2 $\pm 4.4 ; \mathrm{n}=3025$ females $)$ than with vials $(29.9 \pm 3.2 ; \mathrm{n}=492$ females $)$, although there 
was no difference in the fecundity of both groups. Similarly, the size of egg batches appears also to be affected by the type of sugar provided. Flies fed on sucrose or fructose laid significantly more eggs than those fed on maltose or glucose ( $\mathrm{p}$ 0.05 ). However, this assumes that the variation in blood-meal size was the same in each sugar-group, i.e. there was no systematic bias which could have caused the differences in the number of eggs produced in each group. On the other hand, the mean number of eggs found in gravid wild caught females was 33.4 (range 10-43; $\mathrm{n}=140$ females), although this varied between seasons (Fig.).

There were no significant differences in larval hatching between CIDEIM and SAS colonies, in both cases being under $50 \%$. Overall larval mortality was $35.6 \%$, of this mortality presumably due to fungal or mite contamination, that occurred during the first instar represented the highest proportion (Table I). In some instances, proliferation of contaminants was controlled by removal or disruption with needles and reducing pot humidity. However, the control procedures appeared to affect larval survival too. Mortality at the pupa stage was always low.

Bred adults were robust and healthy. Generally, females emerged some hours later than males. Overall female:male ratio was 0.90 though it was male biased in individuals grown in pot culture
(0.81) in contrast with those in vials (1.15). Blood feeding of adults from the first three generations was easily achieved using either hamster or membrane feeder through a chick-skin. Conversely, females from the fourth and fifth generations fed with reluctance or not at all by these methods. A human arm was accepted by flies but not in all instances.

It appears that sandfly survival was affected by the type of sugar offered. The cumulative mortality at $48 \mathrm{hr}$ was significantly higher $(\mathrm{p}<0.05)$ in flies fed on maltose and glucose than either fructose and sucrose; all flies died in all groups, the majority of them immediately after oviposition when a wet surface was provided. However, the former groups (maltose and glucose) died after six days whilst some flies fed on fructose survived to eight days.

Attempts to colonize Lu. evansi under the local conditions of SAS showed more promising results than in Cali. Firstly there was a slight reduction in the length of the cycle $(40.3 \mathrm{~d} \pm 1.88$; range $=37-44)$; secondly, an increase in the proportion of females (female: male ratio $=1.3$ ) and finally, an increase in the mean number of eggs developed ( 30.5 eggs $\pm 14.56 ; n=370$ females). On the other hand, there were strong limitations to the colony; in descending order of importance, no hatching and/or death during first larval instar, fungal contamination and ant predation.

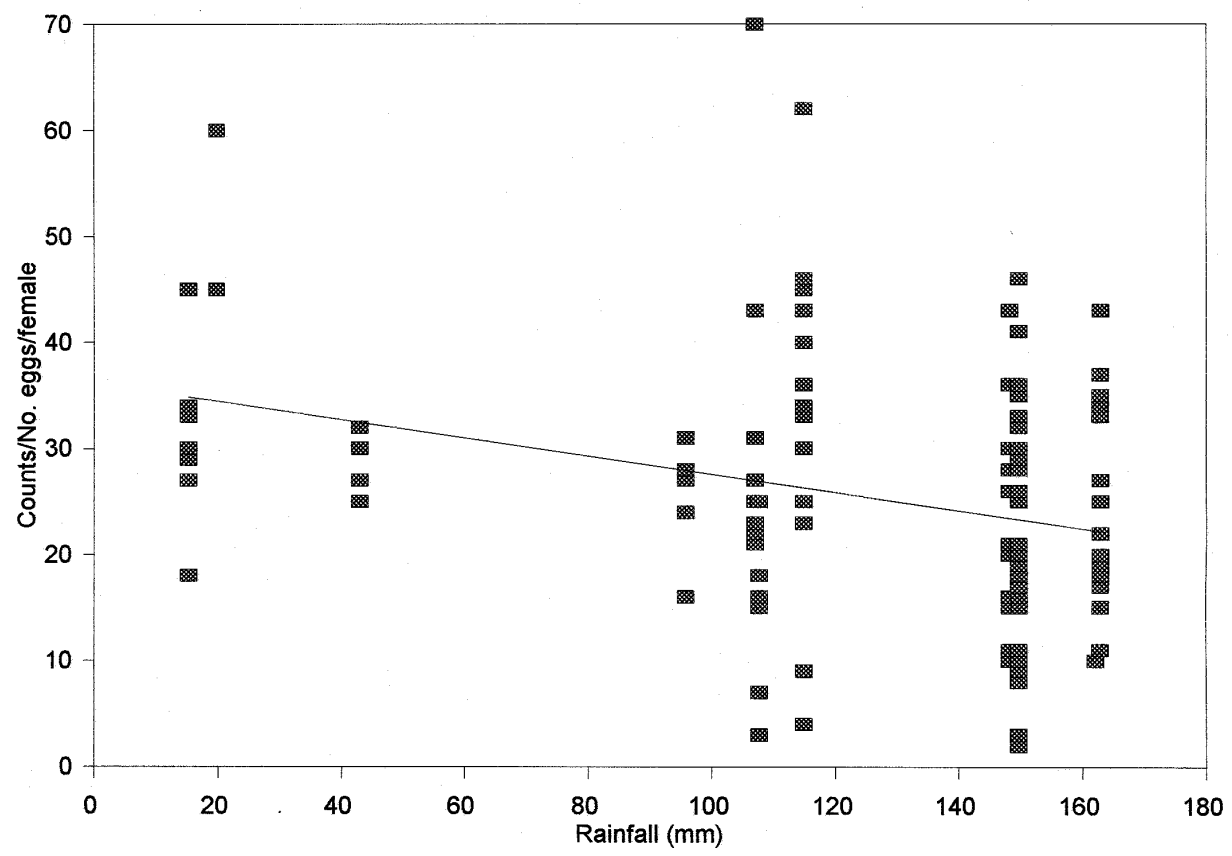

Regression line of the number of eggs found in wild caught Lutzomyia evansi $(\mathrm{y}=36.16-0.085 \mathrm{X} ; \mathrm{p}<0.005)$. 


\section{TABLE I}

Summary of the main events in the colonization of Lutzomyia evansi under lab conditions in (A) CIDEIM and (B) San Andrés de Sotavento, Colombia

\begin{tabular}{|c|c|c|c|c|c|c|c|c|}
\hline & \multirow{2}{*}{$\begin{array}{l}\text { Females } \\
\qquad \mathrm{N}(\overline{\mathrm{x}})\end{array}$} & \multirow{2}{*}{$\begin{array}{l}\text { Eggs laid } \\
\qquad N(\bar{x})\end{array}$} & \multirow{2}{*}{$\begin{array}{c}\text { Larvae } \\
\text { hatched } \\
\mathrm{N}(\%)\end{array}$} & \multicolumn{2}{|c|}{ Mortality } & \multicolumn{2}{|c|}{ Adults } & \multirow{2}{*}{$\begin{array}{c}\text { Increase } \\
\text { rate }\end{array}$} \\
\hline & & & & $\mathrm{L}_{1}$ & $\mathrm{~L}_{1} \rightarrow \mathrm{L}_{4}$ & Females & Males & \\
\hline \multicolumn{9}{|l|}{$\overline{\mathbf{A}}$} \\
\hline $\mathrm{P}_{1}$ & $\begin{array}{c}886 \\
(177.2)\end{array}$ & $\begin{array}{l}10904 \\
(12.3)\end{array}$ & $\begin{array}{l}2280 \\
(21)\end{array}$ & $\begin{array}{l}570 \\
(25)\end{array}$ & $\begin{array}{l}51 \\
(22)\end{array}$ & $\begin{array}{c}754 \\
(075)\end{array}$ & 997 & 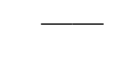 \\
\hline \multirow[t]{2}{*}{$\mathrm{F}_{1}$} & 632 & 12599 & 4438 & 479 & 99 & 1819 & 2041 & 0.85 \\
\hline & $(126.4)$ & (19.9) & $(35.2)$ & (10.8) & $(2.5)$ & $(0.89)$ & & \\
\hline \multirow[t]{2}{*}{$\mathrm{F}_{2}$} & 668 & 9074 & 3979 & 632 & 592 & 1171 & 1584 & 2.41 \\
\hline & (133.6) & (13.6) & (43.9) & (15.9) & $(17.7)$ & $(0.73)$ & & \\
\hline \multirow[t]{2}{*}{$\mathrm{F}_{3}$} & 849 & 7569 & 2869 & 2322 & 218 & 112 & 104 & 0.64 \\
\hline & (169.8) & $(8.9)$ & (37.9) & $(80.1)$ & (39.9) & (1.07) & & \\
\hline \multirow[t]{2}{*}{$\mathrm{F}_{4}$} & 31 & 1020 & 405 & 101 & 6 & 112 & 186 & 0.09 \\
\hline & $(6.2)$ & (32.9) & $(39.7)$ & $(24.9)$ & (2) & $(0.6)$ & & \\
\hline \multirow{2}{*}{$\mathrm{F}_{5}$} & 41 & 609 & 262 & 24 & 0 & 123 & 115 & 1 \\
\hline & $(8.2)$ & (14.9) & $(43.0)$ & $(9.2)$ & (0) & $(1.06)$ & & \\
\hline \multirow[t]{2}{*}{ Total } & 3107 & 41775 & 14233 & 4128 & 966 & 4102 & 5027 & \\
\hline & & (13.4) & (34) & (29) & (9.6) & \multicolumn{2}{|c|}{$(0.81)$} & \\
\hline \multicolumn{9}{|l|}{ B } \\
\hline \multirow[t]{2}{*}{$P_{1}$} & 50 & 3906 & 994 & 460 & 0 & 230 & 156 & - \\
\hline & $(25)$ & (7812) & $(25.5)$ & $(46.3)$ & (0) & $(1.47)$ & & \\
\hline \multirow[t]{2}{*}{$\mathrm{F}_{1}$} & 116 & 2442 & 1381 & 130 & 12 & 791 & 448 & 3.43 \\
\hline & (58) & (21) & $(56.5)$ & $(9.4)$ & (1) & $(1.76)$ & & \\
\hline \multirow[t]{2}{*}{$\mathrm{F}_{2}$} & 110 & 2114 & 834 & 253 & 0 & 239 & 342 & 0.3 \\
\hline & (55) & (19.2) & $(39.5)$ & $(30.3)$ & $(0)$ & $(0.69)$ & & \\
\hline \multirow[t]{2}{*}{$\mathrm{F}_{3}$} & 144 & 2825 & 1369 & 199 & 22 & 586 & 562 & 2.45 \\
\hline & (77) & (19.6) & $(48.5)$ & $(14.5)$ & $(1.9)$ & (1.04) & & \\
\hline \multirow[t]{2}{*}{ Total } & 370 & 11287 & 4578 & 1042 & 34 & 1846 & 1508 & \\
\hline & & (30.5) & (40.6) & (22.8) & $(0.96)$ & \multicolumn{2}{|c|}{$(1.22)$} & \\
\hline
\end{tabular}

$(\bar{x})$ : mean

TABLE II

Duration (in days) of different instars in various attempts to colonize Lutzomyia evansi in Colombia (San Andrés de Sotavento and Cali) and Venezuela [Trujillo (Oviedo et al. 1995) and Altagracia (Mirsa 1953)]

\begin{tabular}{lccccccc}
\hline Strain & $\mathrm{E} \rightarrow \mathrm{L}_{1}$ & $\mathrm{~L}_{1} \rightarrow \mathrm{L}_{2}$ & $\mathrm{~L}_{2} \rightarrow \mathrm{L}_{3}$ & $\mathrm{~L}_{3} \rightarrow \mathrm{L}_{4}$ & $\mathrm{~L}_{4} \rightarrow \mathrm{P}$ & $\mathrm{P} \rightarrow \mathrm{A}$ & Total \\
\hline Colombia & & & & & & & \\
San Andrés & 6.5 & 6.1 & 3.8 & 6 & 10 & 9 & 41.4 \\
Cideim & 6 & 7 & 6 & 6 & 10 & 9 & 44 \\
Venezuela & & & & & & & \\
Trujillo & 6.8 & 7.2 & 4 & 6.5 & 7.9 & 8.1 & 40.5 \\
Altagracia & 10 & 9 & 9 & 9 & 9 & 5 & 51
\end{tabular}

SAS: $28^{\circ} \mathrm{C}-90 \% \mathrm{RH}$; Cali: $25^{\circ} \mathrm{C}-90 \% \mathrm{RH}$; Trujillo: $26^{\circ} \mathrm{C}-90 \% \mathrm{RH}$; Altagracia: $28.6^{\circ} \mathrm{C}-90 \% \mathrm{RH}$

\section{DISCUSSION}

The life cycle of $L u$. evansi in the laboratory appears to be similar to that recorded in other colonized sandfly vectors viz. Lu. longipalpis (KillickKendrick et al. 1977); Lu. intermedia (Rangel et al. 1985); Lu. whitmani (Barretto 1941), Ph. papatasi (Pandya 1980, Modi \& Tesh 1983) and
Ph. argentipes (Ghosh \& Battacharya 1989) but strongly contrasts with that reported for other Verrucarum species such as Lu. youngi (Castro \& Scorza 1977, Añez \& Oviedo 1985) and $L u$. columbiana (Cadena \& Montoya, unpub. data).

The duration of the entire life cycle of $L u$. evansi reported here confirms the preliminary observations of Mirsa (1953), who found that over a range of 
temperatures and relative humidity, this species had a development time between 31 and 51 days. Our results are also consistent with the data recently reported by Oviedo et al. (1995) who colonized Venezuelan $\mathrm{Lu}$. evansi at $26^{\circ} \mathrm{C}$ and $90 \% \mathrm{RH}$ (Table II).

Despite our successful colonization of other sandfly species ( $L u$. longipalpis, Lu. gomezi, $L u$. lichyi) in the laboratory in Cali, we could not culture $L u$. evansi beyond the fifth generation. In addition to the inherent problems associated with colonization of wild caught specimens (e.g. female egg retention, larval loses due to fungus or mite contamination, etc.) the main challenge to our colony was the reluctance of females of the fifth generation to feed on the blood sources provided. Even when some did feed and eggs developed, they did not oviposit. Our experience was in strikingly contrast to Oviedo et al. (1995) who claimed a high productivity from their colony, currently in its 10th consecutive generation. Interestingly, it appears that Oviedo et al. (1995) experienced a similar "bottleneck" when feeding flies on fourth or fifth generation, especially those grown up with diets rich in protein (i.e. desiccated Artemia salina in powder or a mixture 1:1 of this diet plus an aged mixture of rabbit chow, rabbit feces and coffee leaves). As a possible explanation for this, they invoked the works of Hertig and Johnson (1961); Johnson and Hertig (1961) and Forattini (1973). These authors suggested that perhaps a component of the diet or some micro-organisms developing in the diet might have negative influence on the feeding behavior of colonized sandflies. Since the coffee leaves were the only obvious difference found when we compared our and their used diets, it is likely that the key factor must be present in these plant leaves. However, more work it is needed to clarify this issue. Nevertheless, based on the overall evidence, we suspect that the Venezuelan species has more adaptability to lab conditions than the Colombian counterpart, which appears to be a stenogamic species. Such variation in adaptability between different populations of even the same species is not a rare phenomenon in sandflies, rather it has been observed by several workers in their attempts to colonize both Old and New World species (Dr RP Lane, pers. comm.).

Another factor which needs to be resolved for the successful colonization of Colombian $L u$. evansi is egg retention by females. Results of dissection of individually kept females from the controlled experiments using different sugars, revealed that fully blood-fed female $\mathrm{Lu}$. evansi can develop up to $60 \mathrm{eggs} / \mathrm{batch}$, contrasting greatly with the mean number of eggs laid per female in our cultures (potted females $=11.63$ eggs; vialled females $=32.57$ eggs). It is important to note that the mean number of eggs found in wild females caught by sticky traps over nine months was similar to that observed in laboratory bred females. However, when a scatter diagram was drawn for the number of matured eggs per female against the rainfall pattern, the line was highly suggestive that in nature there is a seasonal variation associated with the environmental conditions. Thus, the drier the environmental conditions the larger the batch of eggs developed by Lu. evansi females (Fig.).

The importance of sugar (sucrose) intake for egg production in $\mathrm{Lu}$. longipalpis was demonstrated by Ready (1979) but there have been few studies on the relative importance of different sugars (c.f. Chaniotis 1974). Besides finding a similar effect in Lu. evansi, our results also suggested that fructose as well as sucrose increased female longevity and vitellogenesis in Lu. evansi.

\section{ACKNOWLEDGMENTS}

To Mr N Perez and A Velasques for their assistance in field sandfly collections. To Mr J Palta for lab maintenance.

\section{REFERENCES}

Añez N, Oviedo M 1985. Two new larval diets for rearing sandflies in the laboratory. Trans $R$ Soc Trop Med Hyg 79: 739-740.

Barretto MP 1941. Sobre a astenobiose do Phlebotomus whitmanni Antunes e Coutinho, 1939 (Diptera: Psychodidae). Rev Bras Biol 1: 305-310.

Bendezu H, Moreno G, Villegas E, Oviedo M 1995. Bionomía de los vectores de leishmaniasis visceral en el Estado Trujillo, Venezuela. V. Preferencias alimentarias de poblaciones silvestres Lutzomyia longipalpis y Lu. evansi. Bol Dir Malariol San Amb 35 (Suppl. 1): 45-52.

Castro TA , Scorza JV 1977. Cultivo de Lutzomyia townsendi (Ortiz, 1959), (Diptera: Psychodidae) a partir de una población alópatrica del Estado Mérida, Venezuela. Bol Dir Malariol San Amb 17: 224-229.

Chaniotis B 1974. Sugar-feeding behavior of Lutzomyia trapidoi (Diptera: Psychodidae) under experimental conditions. J Med Entomol 11: 73-79.

Forattini OP 1973. Entomología Médica. IV. Psychodidae, Phlebotominae, Leishmanioses, Bartenoloses. Edgar Blucher Ed., São Paulo, 658 pp.

Ghosh KN, Battacharya A 1989. Laboratory colonization of Phlebotomus argentipes (Diptera: Psychodidae). Ins Sci \& Appl 10: 551-555.

Hertig M, Johnson PT 1961. The rearing of Phlebotomus sand flies (Diptera: Psychodidae). I. Technique. Ann Ent Soc Am 54: 753-764.

Johnson PT, Hertig M 1961. The rearing of Phlebotomus sand flies (Diptera: Psychodidae). II. Development and behavior of Panamanian sand flies in laboratory culture. Ann Ent Soc Am 54: 764-776.

Killick-Kendrick R, Leaney AJ, Ready PD 1977. The establishment, maintenance and productivity of a laboratory colony of Lutzomyia longipalpis (Diptera: 
Psychodidae). J Med Entomol 13: 429-440.

Killick-Kendrick R, Maroli M, Killick-Kendrick M 1991. Bibliography on the colonization of phlebotomine sandflies. Parassitologia 33 (Suppl. 1): 321-329.

Lawyer PG, Rowton DE, Perkins PV, Johnson RN, Young DG 1991. Recent advances in laboratory mass rearing of Phlebotomine sand flies. Parassitologia 33 (Suppl. 1): 361-364.

Mirsa A 1953. Sobre la biología de algunos flebótomos (Diptera: Psychodidae) y datos sobre otros hemátofagos colectados en Altagracia de Orituco (Estado Guárico), Venezuela. Rev San Asist Social 18: 789796.

Modi GB, Tesh RB 1983. A simple technique for mass rearing Lutzomyia longipalpis and Phlebotomus papatasi (Diptera: Psychodidae) in the laboratory. $J$ Med Entomol 20: 568-569.

Montoya-Lerma J, Lane RP 1996. Factors affecting host preference of Lutzomyia evansi (Diptera: Psychodidae), a vector of visceral leishmaniasis in Colombia. Bull Entomol Res 86: 43-50.

Morrison AC 1994. Field Studies on the Ecology of the Sand Fly Lutzomyia longipalpis (Diptera: Psychodidae) at an Endemic Focus of American Visceral Leishmaniasis in Colombia. PhD Thesis, Yale Uni- versity, xvii + $256 \mathrm{pp}$.

Oviedo M, Moreno G, Graterol D 1995. Bionomía de los vectores de leishmaniasis visceral en el Estado Trujillo, Venezuela. III. Colonización de Lutzomyia evansi. Bol Dir Malariol San Amb 35 (Suppl. 1): 269- 276.

Pandya AP 1980. Laboratory breeding of the sandflies Phlebotomus argentipes Annandale \& Brunetti and P. papatasi Scopoli. Indian J Med Res 72: 64-65.

Rangel EF, de Souza NA, Wermenlinger DE, Barbosa AF 1985. Estabelecimento de colonia, em laboratório, de Lutzomyia intermedia Lutz \& Neiva, 1912 (Diptera: Psychodidae, Phlebotominae). Mem Inst Oswaldo Cruz 80: 219-226.

Ready PD 1979. Factors affecting egg production of laboratory-bred Lutzomyia longipalpis (Diptera: Psychodidae). J Med Entomol 16: 413-423.

Tesfa-Yohannes TM 1982. Reproductive biology of Aedes (S.) malayensis (Diptera: Culicidae). J Med Entomol 19: 29-33.

Travi BL, Vélez ID, Brutus L, Segura I, Jaramillo C, Montoya J 1990. Lutzomyia evansi, an alternate vector of Leishmania chagasi in a Colombian focus of visceral leishmaniasis. Trans $R$ Soc Trop Med Hyg 84: 676-677. 